\title{
Knowledge Representation of Mathematics Education Program among Students in Euclidean Parallelism
}

\author{
Lailatul Mubarokah ${ }^{1,2}$, Cholis Sa'dijah ${ }^{1}$, I Nengah Parta ${ }^{1}$, I Made Sulandra ${ }^{1}$ \\ ${ }^{1}$ Malang State University, 5 Semarang Road, Sumbersari, Lowokwaru, Malang, Indonesia \\ ${ }^{2}$ STKIP PGRI Sidoarjo, Kemiri Road, Kemiri, Sidoarjo, Indonesia
}

\begin{abstract}
This research aims to reveal students' perception-based knowledge representation from mathematics programs in Euclidean Parallelism. Students were asked to do parallelism exercises presented in a verbal and picture form. The data were analyzed by knowledge representation theory based on meaning and perception. There were students who have amodal-multimodal-transition hypothesis. Students' assumptions about the verbal and picture information of not-perfectly-drawn parallel lines varied: assuming that angles appear to be the same measure are congruent, the two lines would intersect, considering the two lines parallel but redrawing picture to determine the pair of congruent angles and using other perspectives to interpret the picture. This study recommends action research for geometry learning that provides not-perfectly-drawn parallel lines for students who have amodal and amodalmultimodal-transition hypothesis and observe its effect on their non-Euclidean geometry learning. It may also familiarize students with getting to know parallelism in $\mathbf{R}^{3}$.
\end{abstract}

DOI: $10.18421 /$ TEM103-17

https://doi.org/10.18421/TEM103-17

Corresponding author: Cholis Sa'dijah,

Malang State University, 5 Semarang Road, Sumbersari, Lowokwaru, Malang, Indonesia; Malang State University, 5 Semarang Road, Sumbersari, Lowokwaru, Malang, Indonesia.

Email: cholis.sadijah.fmipa@um.ac.id

Received: 18 March 2021.

Revised: 09 July 2021.

Accepted: 15 July 2021.

Published: 27 August 2021.

(c) BY-NC-ND (C) 2021 Lailatul Mubarokah et al; published by UIKTEN. This work is licensed under the Creative Commons Attribution-NonCommercial-NoDerivs 4.0 License.

The article is published with Open Access at www.temjournal.com
Keywords - Euclidean parallelism, geometry, visual perception, knowledge representation, perceptionbased knowledge representation, meaning-based knowledge representation.

\section{Introduction}

The process of geometry learning cannot be separated from the use of geometry shapes. To help the learning process, teachers present abstract mathematical objects using media, such as pictures. Thus the students can have a concrete observation that makes the mental transformation process more straightforward. The picture used becomes the students' center of attention and reference to identify, classify, and analyze geometry objects. When the figures' mental transformation is more advanced, geometry problems become more difficult [1]. Students' performance in geometry is poor [2] compared to other mathematics domains [3]. Therefore, there is a need to observe students' process in building their geometry knowledge while observing a picture. This observation is not far from how a person perceives what he or she notices.

Someone translates and interprets what they see based on the perception they have made. Perception is about someone's ability to see and translate the information people got using their existing knowledge. Someone's intelligence to see can be seen from the flexibility of their vision to go above the primary feature of visual perception to extract various information levels from the object they are observing [4]. Object representation within our mind is the final result of perception [1].

The representation that is a form of someone's perception can be similar or different from what he has seen. A piece of information can be interpreted as meaning that exceeds the content (Jones, 2008). How the information presented can also affect the representation of someone's knowledge. There are many geometry problems presented in both types of representation at the same time. The information presented in two representations, text and 
picture/visual, can be done in three ways. One of them is through written text (verbal) and pictures that give non-redundant and interrelated information on the whole problem [5]. The information from the text and picture complete each other. Also, verbal and visual information is not processed in the same part of our brain [6].

Mechanism of representation in a symbol perception system plays three roles: representing the physical object in the perception and representing their non-existing object in imaging and conception [7]. Student's mathematics understanding can be developed in translating between and within different representations [8], [9].

When students learn parallel lines, they are faced with two visually parallel lines [1]. Additionally, learning only Euclidean geometry unconsciously habituates students to prove geometry, referring to picture observation, principally the shapes. This happens because students often present pictures to simplify geometry shapes observation. Humans show a stronger tendency to rely on visual information than the other forms of sensory information [1], [10]. A piece of text information is better remembered when it is illustrated in an image than it is not [11]. Geometry proofs are based on logical truths, even if pictures help us estimate the position and visualize the information we need. Based on this explanation, the researchers will reveal the knowledge representation of mathematics program among students in Euclidean parallelism. In this research, the representation is limited to knowledge representation based on perception (especially mental imagery) and meaning.

\section{Knowledge Representation}

Representation considered changing a problematic situation by investigating and developing experiences during that activity [12] to be transformed into the internal mind and external environment [13]. What can be seen in the represented object and how it will be viewed is the representation [14].

There are two types of representations. They are internal and external. The internal representation is the meaning of an individual symbol [15] and a proposition, production, scheme, mental picture, and network connection in someone's mind [13]. Conversely, external representation is related to physical pictures, which are symbols' shapes and positions that can be examined perceptually from the environment [15]. Information obtained from internal and external representations is processed in an integrative, dynamic, and interwoven manner [16]. The knowledge representation in this research was revealed in two ways. They were based on perception and meaning (amodal and multimodal hypothesis) [7], [17].

Perception-based knowledge representation is the knowledge representation associated with the detail of objects being observed [1]. It is not the record on the brain condition that becomes the base of perception [7]. It is rather about what is received by the sensorimotor. The symbol of perception only consists of the schematic aspect from two selective attention, (1) isolating information within perception and (2) saving the information saved in the long-term memory [7]. Therefore, this representation is an internal representation. The perception-based knowledge representation in this research is limited to mental imagery. Mental imagery is the ability to form mental representations of the appearance of objects and to manipulate these representations in mind [18]

On the amodal hypothesis, each part of the unit that establishes meaning representation has to be based on the meaning unit [17]. When an object is as two parallel lines, then the given verbal and picture stimuli are both abstracted with the same meaning. This system transforms the subset from perceptual status into a non-perceptual representation language [7]. The multimodal hypothesis contrasts with an amodal hypothesis. There are various representations related to perception and the motoric system. We have the medium to change a representation into the others directly [17]. There are two parallel lines presented in pictures of two not-perfectly-drawnparallel lines. We will quickly respond by drawing two perfectly-drawn-parallel lines.

\section{Reseach Method}

Students involved in this research came from two different universities, private and state universities, with different abilities. 46 students from the mathematics education study program on the 3 th and 4th levels in 2019 did the researchers' test. The test was presented in the form of verbal and pictures. The problems used in the test can be seen in Figure 1. 
This picture shows two parallel lines $\mathrm{g}$ and $\mathrm{k}$ being intersect with line 1.

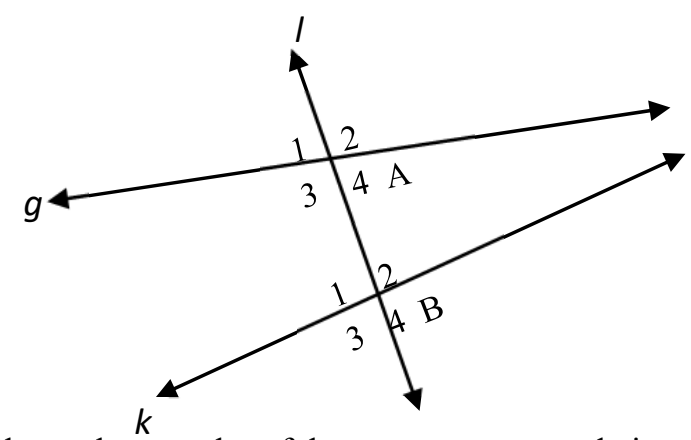

Please show angles of the same measure and give your reason!

Figure 1. The Problem on Euclidean Parallelism Geometry

This problem was aimed to know if the two parallel lines presented in the picture of visually not parallel lines can blur someone's perception about the definition of two parallel lines. Consequently, it affects their knowledge representation. Besides, the measure of angle couples of $A_{1}$ and $B_{3}, A_{3}$ and $B_{1}, A_{2}$ and $\mathrm{B}_{4}$, and $\mathrm{A}_{4}$ and $\mathrm{B}_{2}$ were drawn similarly to distract them visually.

Based on student's answers, five classifications were made in Table 1 based on the types of student answers.

Table 1. Recapitulation of the Results of Participant's Answer Analysis

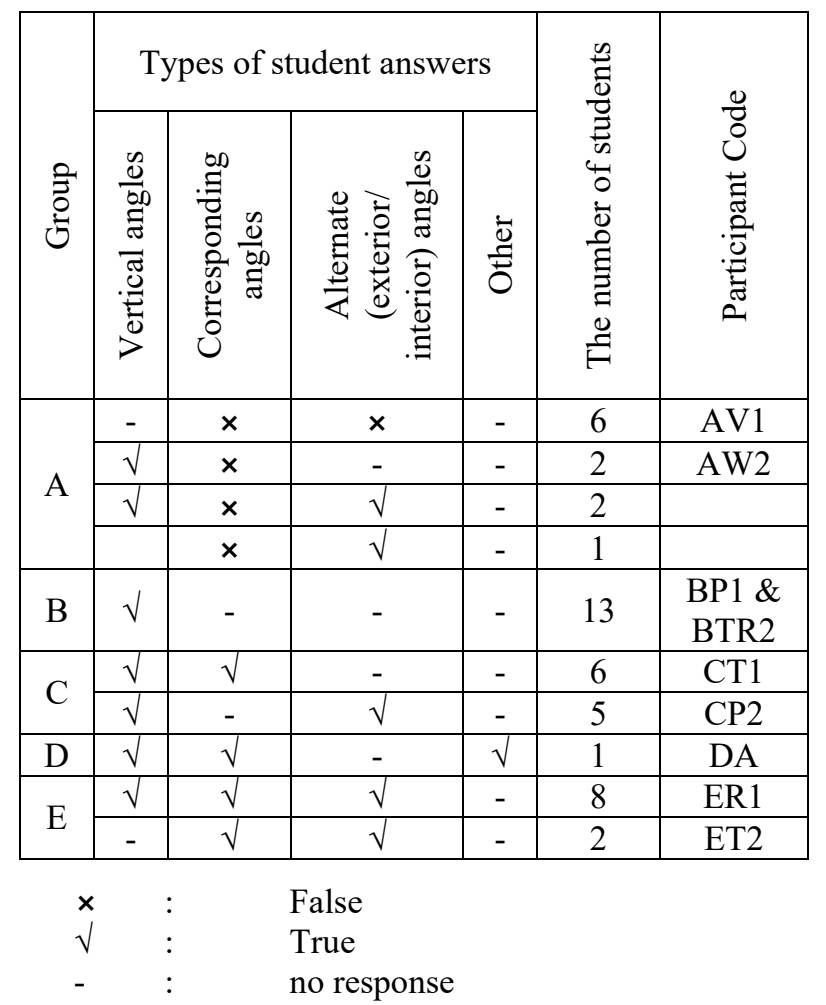

Seven students with different solutions were interviewed until the saturated data was obtained. To analyze, the researchers used knowledge representation theory based on perception and meaning. The perception-based knowledge representation was limited to mental imagery.

\section{Results and Discussion}

Students' knowledge represents Euclidean parallelism from their written answers and interview results that show some indications. The first indication, to accept that line $\mathrm{g}$ and $\mathrm{k}$ are parallel, two students saw it in different perspectives, that they were similar to a railroad if perceived as if they intersect. Two other students showed the second indication. The picture should not represent the hole of information context. For these students, the presented verbal information in geometry is more important to be considered. On the other hand, the other two students showed other indications that they could not say if lines $\mathrm{g}$ and $\mathrm{k}$ were two parallel lines if they were presented as intersecting lines. One of them decided the angles of the lines with the same measure based on the vertical angles, and the other changed them with the picture of perfectly-drawnparallel lines. The last student assumed that the picture showed two parallel lines but decided the pair of angles based on what was seen from the picture.

AW is a participant who made mistakes in deciding the pair of angles based on the visually same measure. AW's written answer can be seen in Figure 2.

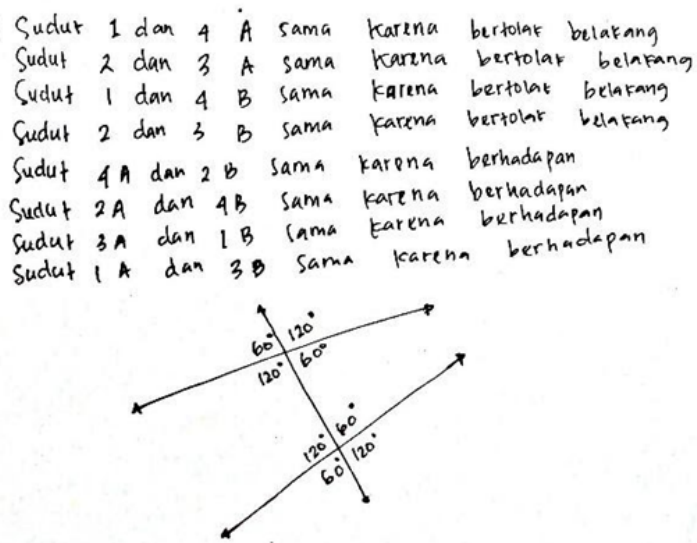

Angle 1 and 2 A are same because vertical angles Angle 2 and $3 \mathrm{~A}$ are same because vertical angles Angle 1 and $4 \mathrm{~B}$ are same because vertical angles Angle 2 and $3 \mathrm{~B}$ are same because vertical angles Angle 4A and 2B are same because opposite angles Angle 2A and 4B are same because opposite angles Angle $3 \mathrm{~A}$ and $1 \mathrm{~B}$ are same because opposite angles Angle 1A and 3B are same because opposite angles

Figure 2. AW's Written Answer 
Figure 2 show that AW simulated the measure of angles.

$$
\begin{aligned}
& \mathrm{P}: \text { : “.. Are these two parallel lines?" } \\
& \mathrm{AW}: \text { "Yes" } \\
& \mathrm{P}: \text { :"These are two parallel lines ... Why?" } \\
& \text { AW : "Yes, because it is stated in the problem Ma'am } \\
& \text {... two parallel lines." }
\end{aligned}
$$

AW used verbal information from the problem to say that the problem picture represents two parallel lines, $g$ and $\mathrm{k}$. Even if in the picture of lines $\mathrm{g}$ and $\mathrm{k}$ were intersect, AW still said that line $\mathrm{g}$ and $\mathrm{k}$ are parallel. AW's mental transformation can be seen in this following interview.

P : "after you read this problem, what did you think?"

AW : "This Ma'am, I saw this line... (while pointing the line $g$ on Figure 1) is 180. "I assumed... this is 60 and this is 120 (pointing to $A_{1}$ then $A_{2}$ )."

The visually-obtuse angles are given a measure bigger than the visually-acute angles.

P : "Which one did you decide first, these were opposite and vertical angles or their measure?

AW : "Deciding the measure first."

P : "This and this, which did you do first?" (Pointing at the pictures made by AW and AW's answers shown above the picture on Figure 2)

AW : "This one." (Pointing at the explanation above the picture made by AW on Figure 2)

P : "Then, how did you decide this?" (Circling AW's explanation on her written answer about the reason for the angles similarity)

AW : "From looking at this, Ma'am." (Pointing at the picture on Figure 1)

P : "Then, when you looked at this (pointing at the picture on Figure 1) based on what did you decide that for example 3 and 1 (pointing at $\mathrm{A}_{3}$ and $\mathrm{B}_{1}$ angles on Figure 1) are congruent?

AW : "opposite angles, Ma'am."

P : "did you remember that they are opposite angles or did you look at the picture first?"

AW : "The picture, first."

P : "Then, why did you decide that 3 and 1 were the congruent?"

AW : "Because they were opposite angles, Ma'am."

P : "Even if there are no pictures, will you still remember that there are vertical angles?"

AW : "Yes."

When the research problem was presented, AW realized a relation between the corresponding angles, etc. AW started solving the problem by looking at the problem first. Based on the shape of the angles, AW remembered the pair of congruent angles are the corresponding angles, etc. After that, AW illustrated her thinking by making a complete picture accompanied by the possible measure of the angles below the written text answer.
When explaining the picture drawn by himself, AW explained the steps that she used to determine the measure of the angles, as follows.

$\mathrm{P}$ : "Then, How did you determine the ones at the bottom?"

AW : "Pointing at the angle on Figure 2 in according to $\mathrm{B}_{1}$ on Figure 1) 120."

P : "120?"

AW : "Yes, because it was bigger (while pointing at the angle on Figure 2 in according to $\mathrm{B}_{1}$ on Figure 2)"

P : "What about this one (pointing at the picture of angle on Figure 2 in according to $A_{1}$ on Figure 1) you wrote 60 first, right, why didn't you start with 60 ?"

AW : "No ... because, that one, Ma'am. It was bigger, so I wrote 120 , first."

P : "Why did you choose 120? Why didn't you choose 130?"

AW : "No, because I followed this, Ma'am." (Pointing at the angle on Figure 2 in according to $A_{2}$ on Figure 1)

$\mathrm{AW}$ assumed that $\mathrm{A}_{2}$ and $\mathrm{B}_{1}$ were bigger than its supplement, then those two angles were considered congruent.

$\mathrm{P} \quad$ : “... I mean among these (pointing at angle on Figure 2 in according to $\mathrm{A}$ and $\mathrm{B}$ on Figure 1). Here, the composition should be 60 and 120, this should be 60 and 120 . Then, here the composition should be 120 and 60, and (while pointing at angle on Figure 2 in according to $B_{1}$ on Figure 1) should this be equated with which angle if we use the angles above?"

AW: "This." (Pointing at angle on Figure 2 in according to $\mathrm{A}_{3}$ on Figure 1)

$\mathrm{P}$ : "Why are these angles congruent?" (Pointing angles on Figure 2 in according to $A_{3}$ and $B_{1}$ on Figure 1)

AW : "They are opposite angles."

P : "What are they opposite angles?"

AW : "That faces each other." (While approaching her hands to each other)

$\mathrm{P}$ : "Then, why do you call these opposite angles? (while pointing at angles on Figure 2 in according to $A_{1}$ and $B_{3}$ on Figure 1 ) if this is 60 and that one is also above 60 , then Why are the ones below opposite angles? What kind of opposite angles"

AW : (Being silent and thinking for a long time) "They are the alternate (exterior or interior) angles, Ma'am."

P : "What are alternate (exterior or interior) angles?"

AW: (while smiling) "Because ... there is a block (pointing at line $\mathrm{g}$ and $\mathrm{k}$ several times on Figure 2) so..."

$\mathrm{P} \quad$ : "Why are these ones called opposite angles (pointing at angle $\mathrm{A}_{3}$ and $\mathrm{B}_{1}$ on Figure 1)?

AW : "Because they are directly, facing each other."

$\mathrm{P}$ : "It means there is no block between them, right?" AW : "right" 
From the quotation above, it can be seen that AW only remembered the term of opposite angles but she did not understand the definition of opposite angles. When she wrote the written answer, AW stated that the couples of $A_{3}$ and $B_{1}, A_{4}$ and $B_{2}, A_{1}$ and $B_{3}$, and $A_{2}$ and $B_{4}$ were the pair of opposite angles. However, according to mathematical concepts, those four pairs are not opposite angles. Then, during the interview, AW changed her reason that $\mathrm{A} 1$ and $\mathrm{B} 3$ were alternate (exterior or interior) angles, which according to the mathematical concept they are not alternate (exterior or interior) angles. AW explained that opposite angles are between line $\mathrm{g}$ and $\mathrm{k}$, there is no block between them. Also, with the term "there is a block" for the angles on the contrary toward line g and $\mathrm{k}$, AW called them alternate (exterior or interior) angles.

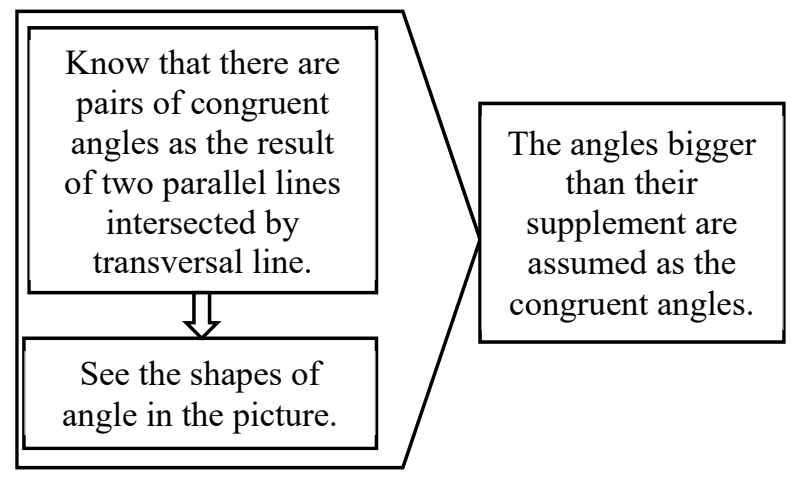

Figure 3. Mental Transformation Process of AW in Determining the Pair of congruent angles

Figure 3 reveals that Aw's knowledge representation is a multimodal hypothesis. Even she noticed that the picture on the problem showed two parallel lines, but in her solution, she determined the pair of angles based on the angles' measure that appeared in the picture.

BTR is a student solving the problem by using only the vertical relation. BTR stated that $\mathrm{g}$ and $\mathrm{k}$ are not parallel lines because the lines will intersect when we extend the lines.

BTR : "We were asked to choose two lines (then, changes his explanation by reading the problem). It states that they are parallel lines. Nevertheless, if we extend the lines, the lines will intersect, so I called them that the congruent angles are the vertical angles."

According to BTR, the information presented verbally and visually contradicts; thus, he argued that the congruent angles are the vertical angles as what he has written in his written answer (Figure 4).

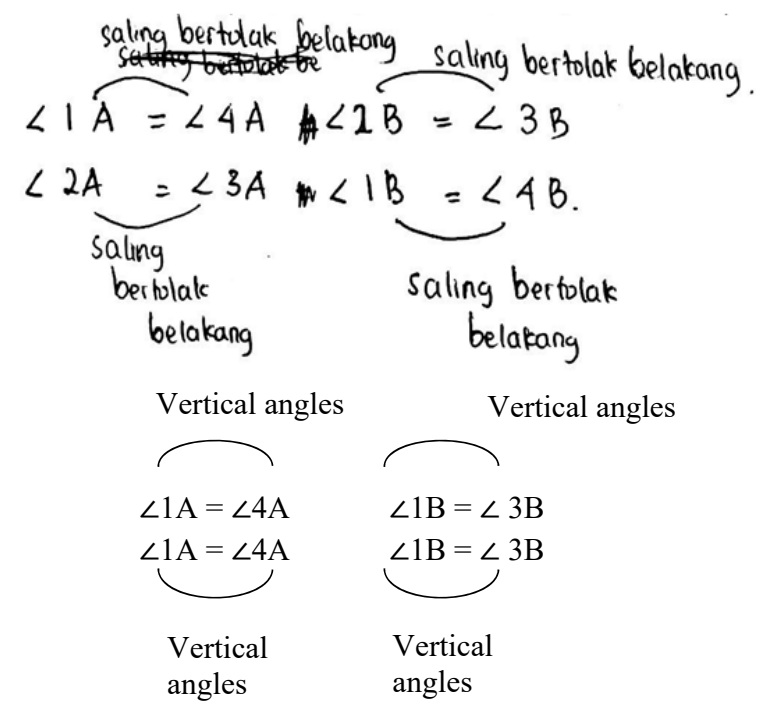

Figure 4. BTR's Written Answer

The mental transformation process of BTR presented in Figure 5 reveals that he also has a multimodal hypothesis. The verbal and picture information is assumed to contradict each other.



Figure 5. Mental Transformation Process of BTR

CT1 is a student solving the problem by utilizing the vertical and corresponding angles. During the interview, CT1 stated that based on the verbal information in which $\mathrm{g}$ and $\mathrm{k}$ were parallel lines, so the representation of both parallel lines was being ignored. CT1 drew perfectly parallel lines. That was mentioned during the interview.

P : "During that moment, how did you decide they are corresponding angles?"

CT1: "Because I did not think this far. I only thought that the pictures were similar, what the name was... It was written two parallel lines g and k."

$\mathrm{P}$ : "So, did you only pay attention to the verbal information?"

CT1: "Yes, not to the picture." 
CT1: "Because it is similar to, for example, when we draw a picture of a triangle, the picture is small, but it is said to be ten centimeters. Isn't it the same? The picture is not ten centimeters, right? It is the same, right?"

CT1 assumed that a picture of two parallel lines does not have to be drawn perfectly as how the picture of a triangle with a particular measure does not have to be presented the same as its verbal information of measure. The similarity between them made CT1 saw that two parallel lines should not be drawn perfectly.

CT1 determined the pairs of angles based on his prior knowledge of vertical and corresponding angles.

CT1: "In my opinion, the $\mathrm{g}$ and $\mathrm{k}$ are parallel lines... then, they are intersected by this line 1 ... I still remember, when I was in junior high school if I do not forget....that The corresponding angles are congruent and the vertical angles also are congruent.

CT1: "So I learned by trying to remember the picture."

$\mathrm{P}$ : "What do you mean by trying to remember the picture?"

CT1: "So, the picture was exactly the same with this, so I just need to mention what I have learned."

P : "Oh, you remember the position, you did not see whether the measure on the picture was the same or not?"

CT1: "Yes, I did not ... (answering the last sentence from the researcher)"

CP2 solved the problem using the vertical and alternate (interior/exterior) angles, which gives a different response from CT1. CP2's problem solving is in Figure 6.

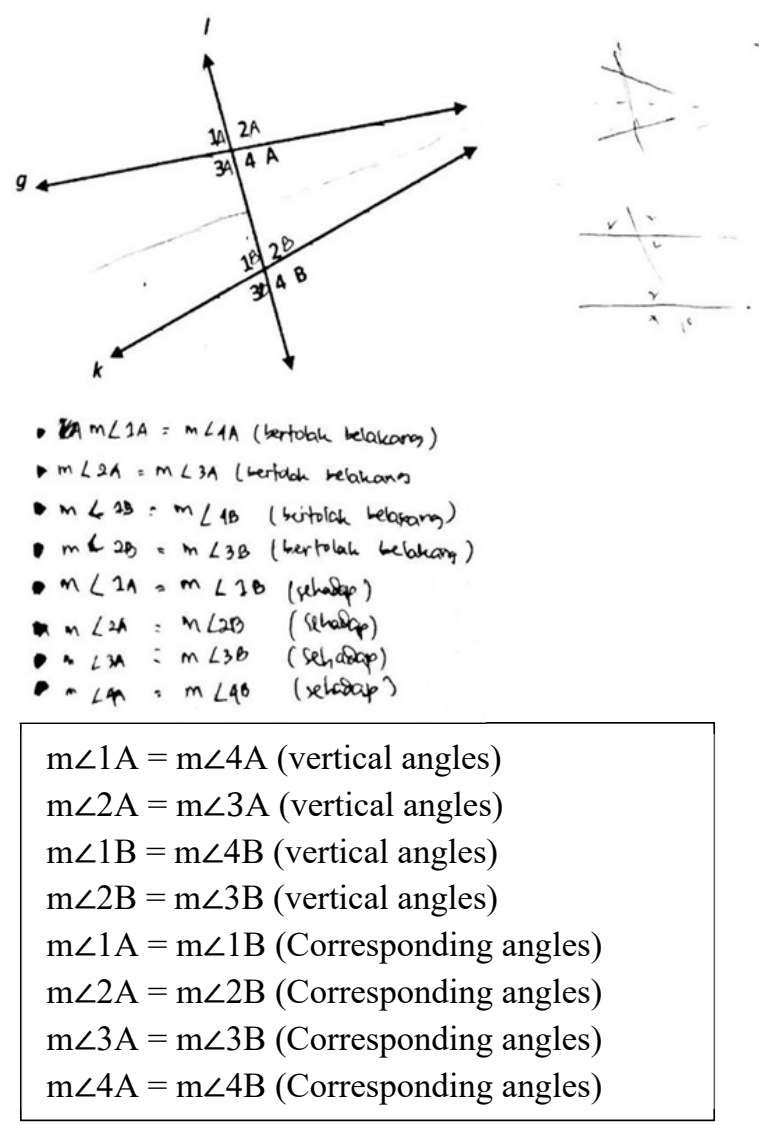

\section{Figure 6. CP2's Written Answer}

Even though they both stated that the picture on the problem in Figure 1 do not represent two parallel lines, CP2 needed a new picture on the right in Figure 6 that he made for himself to determine the couples of the angles.

CP2: "Because I didn't think that the picture is parallel lines, because if we extend this, then (while pointing at the picture on Figure 6 and practicing it by moving his hand as if he extends the line) they intersect."

P : "Okay."

$\mathrm{CP} 2$ : “... the characteristic of two parallel lines is they will not intersect each other at one vertex if we extend them. So, I drew by myself the perfectlydrawn-parallel lines (pointing at the picture on the right he has made by himself on Figure 6). 


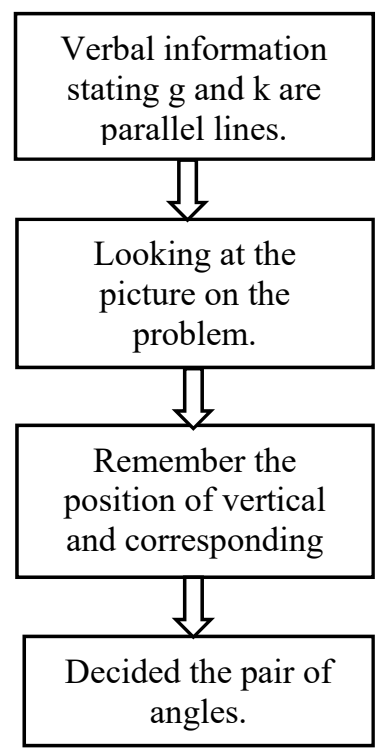

(a) (b)

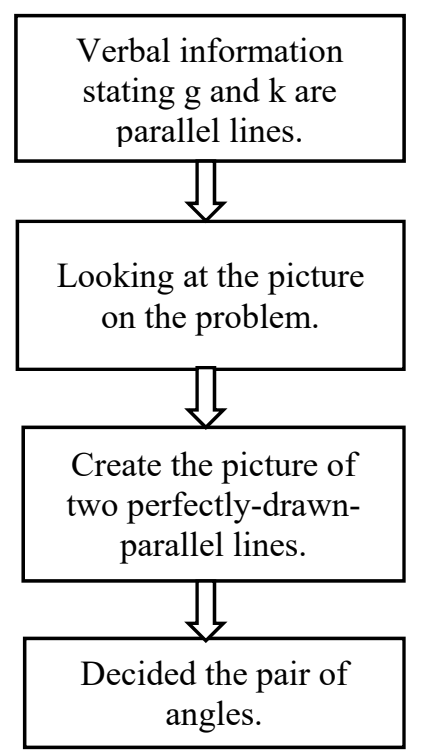

Figure 7. Mental Transformation Process of Group C: (a) CT1 (b) CP2

Based on the description, CT1's mental transformation process is presented in Figure 7. CT1 has an amodal hypothesis in his knowledge representation. Using the picture on the problem, he can determine the pair of angles by using his prior knowledge about the position of the pair of angles. On the other side, based on Figure 7, CP2 has an amodal-multimodal-transition hypothesis. He used his motoric to draw a new picture of two perfectlydrawn-parallel lines to determine the pair of angles.

Students who solved the problem based on vertical angles, corresponding angles, and other reasons are encoded by DA. DA had the same assumption as $\mathrm{CT} 1$. Because the line $\mathrm{g}$ and $\mathrm{k}$ are mentioned as parallel lines in the verbal information, he assumed that the presented picture presents two parallel lines, $\mathrm{g}$, and $\mathrm{k}$.

P : "How was your perception when you saw this picture?"

DA : "Two parallel lines intersected by a transversal line (while demonstrating by his finger making a scratch on the picture."

P : "Did you accept that the lines were parallel lines?"

DA : "I did."

N...

P : "In your opinion, what are parallel lines?"

DA : "The lines that if we extend them, they will not intersect each other at one vertex.

P : "What about this picture?"

DA : "Because the explanation says that they are parallel lines, so I assumed they will not intersect."

DA used his prior knowledge to determine the pair of angles without redrawing the picture.
P : "Then, based on what you determined that the vertical angles are congruent, and the corresponding angles are congruent?

DA : "The lesson I got when I was in school."

P : "You remembered from the past. Which one did you remember, the corresponding angles and the vertical angles or their position? Which one did you remembered first?

DA : "The position. The ones are corresponding angles (while moving his hands twice to the upper right), the ones are vertical angles (while demonstrating the vertical angles)."

P : "Did you need to imagine the shapes of the picture? Because yesterday, there was a student who needed to redraw the picture in order to know which ones were the corresponding angles. What about you?"

DA : "By looking at picture (while pointing at the picture on Figure 1)."

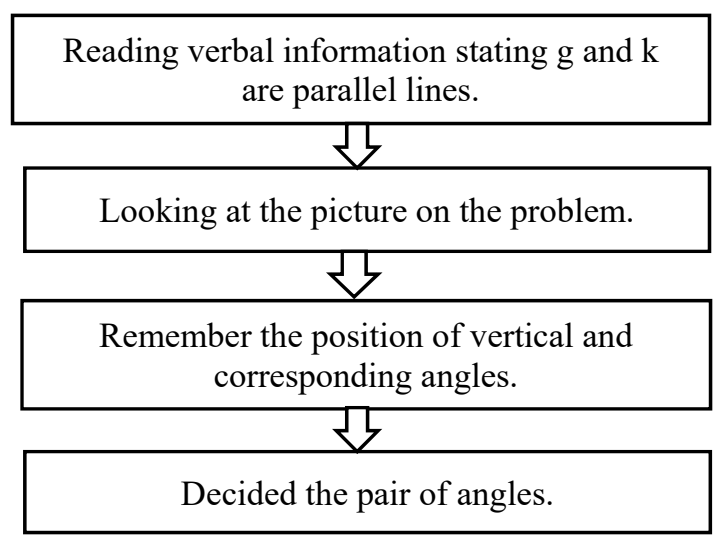

Figure 8. The mental Transformation process of DA

According to Figure 8, the knowledge representation of DA is an amodal hypothesis. He can assume that the picture on the problem showed two parallel lines of $\mathrm{g}$ and $\mathrm{k}$ without redrawing to know the pair of angles.

ER1 and ET2 are the students who solve the problem by facing and corresponding relations. ER1 involved the opposite relation, while ET2 did not. Based on the interview, ER1 saw the picture from a different perspective to be able to say that line $g$ and $\mathrm{k}$ are parallel. ER1, during the interview, mentioned:

P : "Actually, could you accept that the picture is parallel lines?"

ER1: "If just based on the picture alone, I could not. Because here we have verbal information, then I thought that the picture ... how to say it.... It should not be seen from the front, like this (putting his hands in front of his face to illustrate the position of the object) but from here... (inclining his body to one side) or from below..."

P : "So, from this information, you knew that actually they are the parallel lines."

ER1: "Yes."

P : "But with a different perspective." 
ER1 did not need a new picture that he should draw by himself to determine the pair of angles. He just needed to imagine two parallel lines and a transversal line to determine the pair of angles.

ER1: "So this is where I began to observe that $\mathrm{g}$ and $\mathrm{k}$ were parallel lines. Even if ... in this picture, they did not seem parallel lines. Then, here also those two lines were intersected by a straight-line 1 , this was that straight line 1 (while pointing at the line on Figure 1). Then, I remembered that if parallel lines were intersected by a straight line, then there were corresponding angles, vertical angles, supplementary angles, and, alternate exterior and interior angles. So, I chose one angle first, the angle of 2 that intersected between line $\mathrm{g}$ and 1 . Then, because the line $\mathrm{g}$ was parallel to $\mathrm{k}$, and they had the corresponding angle that face here (pointing at the picture on Figure 1 and moving his fingers toward the $A_{2}$ and $B_{2}$ ) then the angle 2 (pointing at $\mathrm{A}_{2}$ ) was congruent with the angle here (pointing at $\mathrm{B}_{2}$ ). This angle and this angle (demonstrating and pointing at angles $\mathrm{A}_{2}$ and $\mathrm{B}_{2}$ on Figure 1). They were corresponding angles."

ER1 remembered a parallelism theorem related to two vertical, corresponding, and alternate exterior/interior angles, then determine which pair of angles have that relation.

ER1: "Right ... to find the alternate interior and exterior angles I used the corresponding and vertical angles."

$\mathrm{P} \quad$ : oo.. So, did You begin from corresponding and vertical angles?

ER1: "The first one, of course, the vertical angles. Because they can be seen if the vertical angles are congruent (while looking at the picture).

In another interview, ER1 explained that he determined the pair of corresponding angles, then vertical angles, and the last determined alternate (interior/exterior) angles.

Mental transformation process of ER1 is presented in Figure 9. Thus, ER1's knowledge representation is an amodal hypothesis.

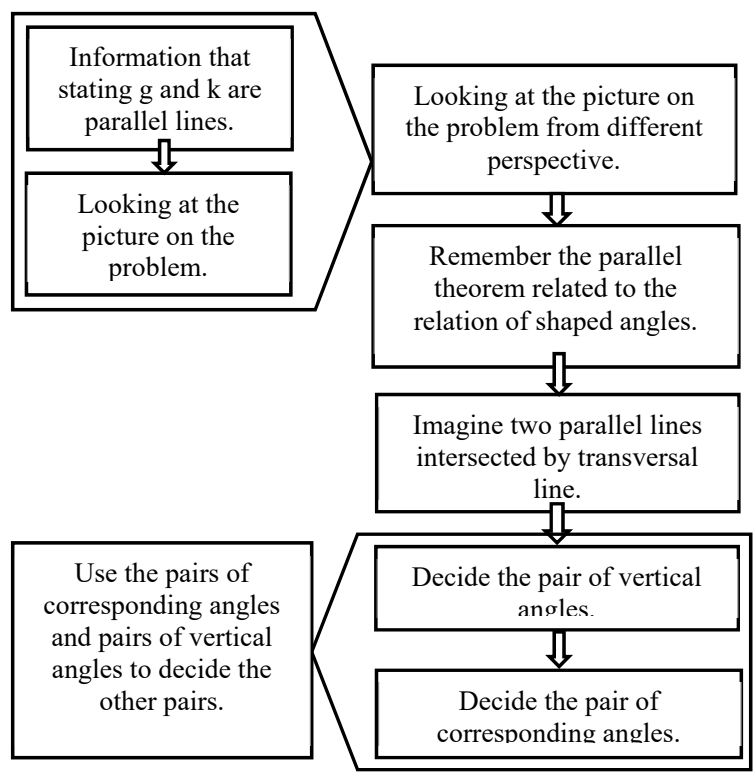

Figure 9. Mental Transformation Process of ER1

Subject ER1 analyzed the picture with different perceptions to assume that the $\mathrm{g}$ and $\mathrm{k}$ were parallel lines as explained in the verbal information. Since the verbal information $\mathrm{g}$ and $\mathrm{k}$ were parallel lines, then ER1 changed his perspective toward $\mathrm{g}$ and $\mathrm{k}$ presented in the problem.

Similarly, ET2 also stated that $\mathrm{g}$ and $\mathrm{k}$ could be said to be two parallel lines if we saw them from a different perspective.

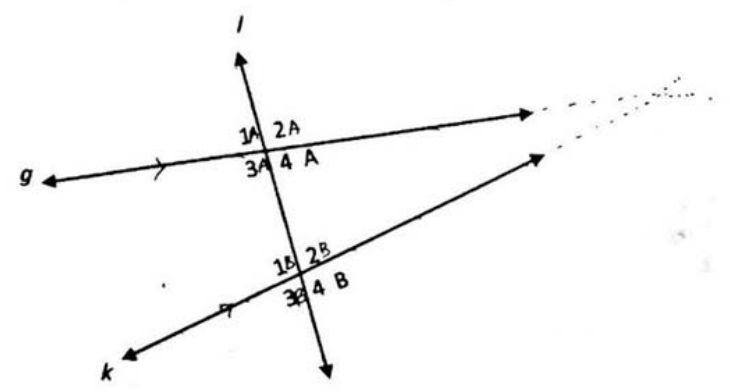

Figure 10. ET2's Note on the Picture on The Problem

ET2 made notes on the problem, as shown in Figure 10. When he was asked about the meaning behind his notes, ET2 defined: 
$\mathrm{P} \quad$ : "Then, what is the meaning of your picture?"

ET2: "This one? (Pointing at the notes on Figure 10) Oh.. no.. I was just imagining, I was trying to remember my high school lesson on that perspective."

P : "All right."

ET2: "So, They surely will be to intersect in a vertex here (pointing at his notes on Figure 10) but in reality it will only be like that, it will be not intersect, so they becomes parallel lines. They are parallel lines but if we look at them from far away, they will seem to intersect in one vertex, but once we observe them, they will not."

ET2 was different from ER1, redrawing picture as CP2's picture on Figure 6 on another paper to help his mental transformation process in determining the pair of congruent angles. ET2 did not give up that paper and just moved his hands in the air to tell his picture described in the following.

ET2: 'Yes, I imagined first if they were parallel (while demonstrating as if his hands represent two parallel lines by putting them in front of his chest) because I forgot which one was the alternate interior angles, so I imagined first if they were really parallel, I mean that the picture was not like this, but was visually parallel lines. Then, I tried to remember again that this was the corresponding angles, then it was the vertical angles (pointing at the picture on Figure 1) then it was alternate interior angles (pointing at the picture on Figure 1), that is my way."

$\mathrm{P} \quad$ : "Ok, did you ever re-draw them or did you just imagine them?"

ET2: "Eeeee.... (trying to remember) I did ever."

Therefore, ET2's mental transformation process is as shown in Figure 11 and the knowledge representation of ET2 is the amodal-multimodaltransition hypothesis.

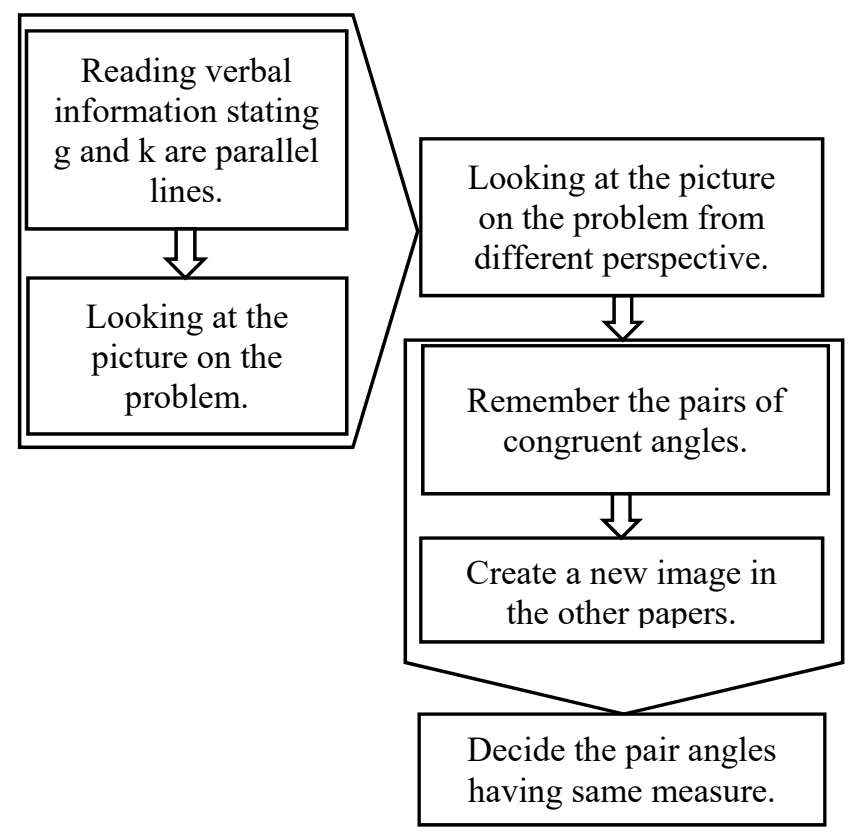

Figure 11. Mental Transformation Process of ET2
Someone's knowledge representation, which results from the perception of the information presented in two ways, verbal and picture, is affected by someone's tendency to focus on a piece of information. Readers' views or attention toward the picture and written information affect the reader's understanding of that information [5]. Prior knowledge is also another factor determining the knowledge representation. This research aims to describe college students' knowledge representation of Euclidean parallelism. The problem is presented in the form of verbal and pictures completing each other information. The results of this research are revealed by knowledge representation theory based on perception and meaning.

Even if they admitted that the problem presented two parallel lines, students who are wrong in determining the pair of congruent angles would focus on the picture problem's angle. Particular representation makes the other information ignored, and it can be relatively hard to be cured [19]. They focused on the form of the angles on the picture problem. Acute angles are assumed as congruent angles, and also obtuse angles are assumed as congruent angles.

Information about the object and environment tourism received relies on the purpose, action, and the observer's attention [20]. Students who solve the problem with the vertical angles perceive the visually not parallel lines will intersect at one vertex. The memory relative to sentences versus the memory for its meaning is based on the verbal representation's relative attention rather than the visual [17]. Communication relies on the context where someone with a low-context culture will focus on the verbal information. In contrast, someone with high-context culture will be more focused on non-verbal information [21]. He used his prior knowledge that two parallel lines should be drawn entirely to respond to a problem. This mental model combines a learner's prior knowledge and new knowledge elements [22]. The perception memory accelerates the perception about the known entity [7]; therefore, when he saw the picture of those lines, he said that they were not parallel lines. This is because pictures have an essential role in his thinking process. The students who used the vertical angles solved the problem based on the picture information. When memory processes a perception, there is a possibility that students have a wrong conceptual understanding that may cause cognitive barriers [23]. Because the picture does not show two parallel lines, according to the geometry theorem, he assumed that only the vertical angles are congruent angles. Humans show a strong tendency to rely more upon visual information rather than the other sensory form of information [1], [10]. 
Additionally, students who use vertical and alternate (interior/exterior) angles as the reference to determine to have to make a new picture to determine the pair of angles. In reality, the low feature guides the eye movement during the inspection and event searching process [24]. The new self-made picture, perfectly-drawn-parallel lines, was used as the reference to determine the pair of congruent angles. It is as being stated by [25] that students for whom a relevant picture is presented learn only slightly more than students for whom an unrelated map is presented.

Students who solve the problem with corresponding and alternate (interior/exterior) angles see pictures through a different perspective, such as railroads. An imagination expands the possibilities of representation [26]. The lines of $\mathrm{g}$ and $\mathrm{k}$ will seem to intersect if they are extended. They focus on the verbal information and their prior knowledge about the theories related to two parallel lines intersected by a transversal line.

Students' knowledge representation, which is making a mistake in determining the pair of angles and determining the pair of angles based on the vertical angles only, is a multimodal hypothesis. Students who can correctly answer the problem are grouped into two categories. Students who need a new picture made by themselves to determine the pair of angles use the multimodal-amodal-transition hypothesis. Previous experience with physical transformations may improve handling mental transformations [1]. On the other hand, students who do not need a new picture have the amodal hypothesis.

\section{Conclusion}

The student's knowledge representation making a mistake in determining the pair of angles uses a multimodal hypothesis. The angles that seemed to be equally acute or obtuse are assumed to have the same measure. Students who determine the pair of angles based on the vertical angles use a multimodal hypothesis. The two lines on the picture are perceived to be intersected. The knowledge representation of students who solve the problem with vertical and corresponding angles use amodal and amodal-multimodal-transition hypothesis. They focus on the verbal information; some did not change the picture, while others changed the picture. Students who work based on the vertical and corresponding angles and other reasons use an amodal hypothesis. The verbal information encourages them to assume that the two lines in the picture are parallel. Students who work based on the facing and corresponding reason use an amodal hypothesis and amodal-multimodal-transition hypothesis. They use a different perspective to interpret the picture.

The long period to learn Euclidean Geometry can affect the memory strength of students' scheme. When they transform from learning Euclidean geometry to learning non-Euclidean Geometry, they can face difficulties at the beginning due to the picture representation they previously used at all the time. The prior knowledge about Euclidean Geometry can obstruct the learning process of nonEuclidean Geometry. The learning result from the learning they have undergone previously are more attached to their scheme and distract the access for the new knowledge they have just learned yesterday [27].

According to the result of this research, the learning practice for students who have amodal and amodal-multimodal-transition hypothesis will be better if teachers start to represent the two parallel lines in visually not parallel lines. Therefore, students will not rely so much on the picture. The effect of that action can be tested on their ease of learning non-Euclidean Geometry, especially the Lobachevski geometry. For the next research, they can research pictures' role in geometry learning and how far students can ignore the pictures when they learn geometry.

\section{References}

[1]. Gal, H., \& Linchevski, L. (2010). To see or not to see: analyzing difficulties in geometry from the perspective of visual perception. Educational studies in mathematics, 74(2), 163-183.

[2]. Kotsopoulos, D., Makosz, S., Zambrzycka, J., \& Cordy, M. (2018). A teacher's judgment of spatial ability. School Science and Mathematics, 118(7), 320331.

[3]. Mullis, I. V., Martin, M. O., Foy, P., \& Arora, A. (2012). TIMSS 2011 international results in mathematics. International Association for the Evaluation of Educational Achievement. Herengracht 487, Amsterdam, 1017 BT, The Netherlands.

[4]. Riley, H. (2017). Drawing as Driver of Creativity: Nurturing an Intelligence of Seeing in Art Students. International Journal of Art \& Design Education, 36(3), 273-280.

[5]. Liwanag, M. P. S. U., Martens, P., Martens, R., \& Pelatti, C. Y. (2017). Examining a reader's meaningmaking process of picture books using eye movement miscue analysis. Literacy Research: Theory, Method, and Practice, 66(1), 248-263.

[6]. Roland, P. E., \& Friberg, L. (1985). Localization of cortical areas activated by thinking. Journal of neurophysiology, 53(5), 1219-1243.

[7]. Barsalou, L. W. (1999). Perceptual symbol systems. Behavioral and brain sciences, 22(4), 577660. 
[8]. Chigeza, P. (2013). Translating between and Within Representations: Mathematics as Lived Experiences and Interactions. Mathematics Education Research Group of Australasia.

[9]. Rahmawati, D., \& Anwar, R. B. (2020). Translation of Mathematical Representation: Characteristics of Verbal Representation Unpacking. Journal of Education and Learning (EduLearn), 14(2), 162-167.

[10]. Sinnett, S., Spence, C., \& Soto-Faraco, S. (2007). Visual dominance and attention: The Colavita effect revisited. Perception \& Psychophysics, 69(5), 673686.

[11]. Levie, W. H., \& Lentz, R. (1982). Effects of text illustrations: A review of research. Ectj, 30(4), 195232.

[12]. Hall, R. (1996). Representation as shared activity: Situated cognition and Dewey's cartography of experience. The Journal of the Learning Sciences, 5(3), 209-238.

[13]. Zhang, J., \& Norman, D. A. (1994). Representations in distributed cognitive tasks. Cognitive science, 18(1), 87-122.

[14]. van Bruggen, J. M., Kirschner, P. A., \& Jochems, W. (2002). External representation of argumentation in CSCL and the management of cognitive load. Learning and instruction, 12(1), 121-138.

[15]. Zhang, J., \& Patel, V. L. (2006). Distributed cognition, representation, and affordance. Pragmatics \& Cognition, 14(2), 333-341.

[16]. Valanides, N., Efthymiou, I., \& Angeli, C. (2013). Interplay of internal and external representations: students' drawings and textual explanations about shadow phenomena. Journal of Visual Literacy, 32(2), 67-84.
[17]. Anderson, J. R. (2004). Cognitive psychology and its implications (6th ed., p. 519). New York: Worth.

[18]. S. M. Kosslyn,. (1995). Mental Imagery, in Visual Cognition An Invitation to Cognitive Science, vol. 2, S. M. Kosslyn and D. N. Osherson, Eds. Cambridge: MA: MIT Press., 1995, pp. 267-296.

[19]. Barlow, H. B. (1983). Vision: A computational investigation into the human representation and processing of visual information: David Marr. San Francisco: WH Freeman, 1982. pp. xvi+ 397.

[20]. Gibson, J. J. (2014). The ecological approach to visual perception: classic edition. Psychology Press.

[21]. Stoian, C. E. (2015). Meaning in Images: Complexity and Variation across Cultures. In Meaning Making in Text (pp. 152-169). Palgrave Macmillan, London.

[22]. Galili, I. (1996). Students' conceptual change in geometrical optics. International journal of science education, 18(7), 847-868.

[23]. Utami, A. D., \& Sa'dijah, C. (2018). Six Levels of Indonesian Primary School Students' Mental Model in Comprehending the Concept of Integer. International Journal of Instruction, 11(4), 29-44.

[24]. Hwang, A. D., Wang, H. C., \& Pomplun, M. (2011). Semantic guidance of eye movements in real-world scenes. Vision research, 51(10), 1192-1205.

[25]. Dean, R. S., \& Kulhavy, R. W. (1981). Influence of Spatial Organization in Prose Learning. Journal of Educational Psychology, 73(1), 57-64.

[26]. Steier, R., Kersting, M., \& Silseth, K. (2019). Imagining with improvised representations in CSCL environments. International Journal of ComputerSupported Collaborative Learning, 14(1), 109-136.

[27]. Underwood, B. (1957). Interference and forgetting. Psychological Review, 64(1), 49-60. 